\title{
COVID-19 vaccine on board ships: current and future implications of seafarers
}

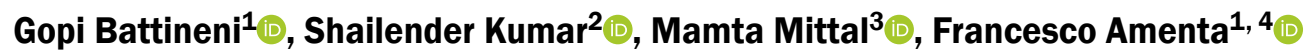 \\ ${ }^{1}$ Telemedicine and Telepharmacy Centre, School of Medicinal and Health Products Sciences, University of Camerino, Italy \\ ${ }^{2}$ Department of Computer Science and Engineering, Delhi Technological University, New Delhi, India \\ ${ }^{3}$ Department of Computer Science and Engineering, G.B. Pant Government Engineering College, Okhla, New Delhi, India \\ ${ }^{4}$ Research Department, International Radio Medical Centre (C.I.R.M.), Rome, Italy
}

The impact and effect of novel coronavirus disease 2019 (COVID-19) are expanding all over the world without boundaries. When it began in China in late 2019, it was seen to be not as scary and devastating as it has become today. However, the hope for overcoming the pandemic lies in finding an effective treatment and inventing a vaccine. If we look at the history of the spread of this contagion, within a short span of seven months it has spread all over the world. Statistics are saying that more than 104 million individuals got infected and 2.2 million deaths were currently occurred [1].

In the last few months, there has been a massive revelation in the medical domain regarding the outbreak of COVID-19 and its vaccination [2]. It has been truly amazing to see scientists and doctors come together across all over the world to share their expertise to develop vaccination in the past few months. Thanks to the collaboration between researchers and scientists are always way ahead to take up challenges and bear the torch of a bright and prosperous future as far as the COVID-19 struggle is concerned. To channelise their potential and encourage them to develop solutions by joining hand together in this pandemic time, the government has also been supportive of various initiatives and funding. Medical doctors sharing their experiences and the patients who have recovered from this near-fatal disease largely help in vaccine development. This brought a whole new perspective on how to handle the current situation the world is facing with the COVID-19 pandemic.

Seafarers are unsung heroes of this pandemic because shipping plays an important role in this serious outbreak. Unfortunately, because of the global emergency that happened in the last year, seafarers went through the depressive symptoms and faced various neuropsychological and psycho-affec- tive alterations [3]. To slow down the rate of onboard infection, various shipping companies provided some serious guidelines such as social distancing at working places, self-hygiene, and room quarantine for any suspicious cases. For some seafarers, this situation is unbearable. Because of the novel pandemic, tens of thousands of sailors were stuck on board for more than a year now. Despite the fact of crew changes have been made conceivable in certain nations, the implementation stays exceptionally challenging. These situations demand immediate access to the vaccine for seafarers.

The speakers in the CrewConnect Global Virtual Event 2020 highlighted that, with some vaccine trials now showing promising results, sailors need to be treated as fundamental workers and be among the first to get vaccine [4]. "I think all the work we've done in lobbying governments now needs to be even more concerted effort about the point that seafarers are essential workers... we need to find a way to find a way to access vaccines" said Mr Stephen Cotton, general secretary of International Transport Workers Federation [4].

Some countries, such as Singapore, already started vaccination for seafarers and it becomes one of the first nations to give importance for COVID-19 vaccine to frontline workers of maritime. According to the Maritime and Port Authority of Singapore, seafarers need to undergo fewer testing before getting vaccinated. It is scheduled that at least 10,000 seafarers can be vaccinated by the end of January 2021 under air vaccination exercise [5].

COVID-19 is considered a type of pneumonia which can be effectively treated by vaccination. All national bodies have to step forward and take Singapore as an example in the provision of vaccine for frontline workers such as seafarers. On other hand, the International Maritime Or- 
ganization also urges that maritime workers and seafarers have to obtain COVID-19 vaccination on a priority basis to allow them to work freely and sustain dynamic global supply chain.

\section{ACKNOWLEDGEMENTS}

This paper was supported in part by the ITF Trust grant No. 1508/2020 to Centro Internazionale Radio Medico (C.I.R.M.).

\section{REFERENCES}

1. Home - Johns Hopkins Coronavirus Resource Center. https:// coronavirus.jhu.edu/ (Feb 02, 2021).
2. Li Q, Lu H. Latest updates on COVID-19 vaccines. Biosci Trends. 2021; 14(6): 463-466, doi: 10.5582/bst.2020.03445, indexed in Pubmed: 33390384.

3. Battineni G, Sagaro GG, Chintalapudi N, et al. Assessment of awareness and knowledge on novel coronavirus (COVID-19) pandemic among seafarers. Healthcare (Basel). 2021; 9(2), doi: 10.3390/ healthcare9020120, indexed in Pubmed: 33503921.

4. CrewConnect, Shipping needs to ensure seafarers prioritised for vaccines. https://www.seatrade-maritime.com/regulation/shipping-needsensure-seafarers-are-prioritised-covid-19-vaccines (Feb 02, 2021).

5. Singapore to prioritise maritime workers in Covid-19 vaccination effort | TradeWinds. https://www.tradewindsnews.com/people/ singapore-to-prioritise-maritime-workers-in-covid-19-vaccinationeffort/2-1-940231 (Feb 02, 2021). 